\title{
Modeling Analysis of Bullwhip Effect in Supply Chain based on Auto-regressive Analysis
}

\author{
Xiangyu Li \\ China Business Council for Sustainable Development, Beijing100035 \\ huner2011@foxmail.com
}

Keywords: Supply chain, Bullwhip Effect, Auto-regressive analysis

\begin{abstract}
With development of economic globalization, people have realized gradually that competition among enterprises has converted to competition among supply chain. Based on this condition, research on supply chain home and abroad is heating up gradually at present, while efficiency of the supply chain is the hot point in it. As one of the most notable phenomena influencing the supply chain, Bullwhip Effect has been paid great attention. It refers to the phenomenon that requirement information of end user on the supply chain goes along the supply chain and gradually expands upstream. Due to it causes a series of problems such as chaos in production and management, increase of inventory as well as occupation of capital, which has seriously influenced business efficiency of enterprises. Therefore, conducting systematic analysis and comprehensive research on it has important theoretical and practical significance.
\end{abstract}

\section{Introduction}

Supply chain management has become an effective way to strengthen competitiveness of enterprises, enterprises set the whole supply chain as the starting point in considering production and operation activities as a whole, this can enhance enterprises competitiveness to make them win in the competition. Market competition during $21^{\text {st }}$ century is no longer the competition among enterprises but among supply chains.Bullwhip Effect in supply chain refers to the requirements of end users gradually expand upstream with the supply chain. This is also the problem of distortion during the transfer of demand information in supply chain. It makes inventories of enterprises in supply chain increase greatly but effective demands downstream cannot be always satisfied, which finally leads to loss of supply chain sales. Due to great harm of Bullwhip Effect in supply chain management hinders development of the supply chain, therefore, it has become the research focus of scholars. How to weaken Bullwhip Effect has become a significant problem in supply chain management; weakening and overcoming this notable problem in supply chain thorough effective way will have practical value and theoretical significance on development of modern enterprises to supply chain. Therefore, it must strengthen research on relevant theories of Bullwhip Effect and weaken its harms and creates conditions for application of modern management method. Settlement of Bullwhip Effect has become the decisive factor in enhancing efficiency of supply chain and realizing competitive edge of supply chain.

\section{Bullwhip Effect in two-level supply chain based on AR(1)demand}

Model hypothesis and prerequisite. The search subject in this section is an easy two-level supply chain system which is composed of 1 retailer and 1 manufacturer. Suppose that retailer is the only buyer of the manufacturer, there is only one kind of product traded between them. Actions of both parties occur within infinite and discrete time frame, that is $t=-\infty, \ldots,-1,0,1, \ldots, \infty$. The time of retailer from sending the order to receiving the goods(time in advance) $L$ [1][2].

There are many methods used to simulate end customer demands including from easy independent identically distributed to a series of dynamic and unstable intermediate procedures. Practice proves that there is no demand prediction method could reflect realistic conditions 
completely and truly. Due to AR(1) simulated end customer demand is relatively mature and not so difficult to compute, therefore, it has become the priority of many scholars.

Meanwhile there are various kinds of demand prediction methods that the retailer could adopt, for instance, SMA, DMA, SES, BSES, HDES as well as WSES. This section only adopts SMA.

$\mathrm{AR}(1)$ is short for Auto-regressive Process of order 1, that is, first-order autoregressive model, in which 1 represents the lag order number of the variable is 1 . AR model is a kind of linear prediction, that is, known $\mathrm{N}$ data and introducing data in front of or behind $\mathrm{N}$ from the model, its nature is similar to interpolation, its purpose is to increase effective data, only AR model is recursion from $\mathrm{N}$ while interpolation is to deduce many points from two points(or few points), therefore, AR model is better than interpolation in effect[3].

Suppose that the requirement of end customer confronted with the retailer is an easy and stable AR(1) auto correlation time series:

$D_{t}=\mu+\rho D_{t-1}+\varepsilon_{t}, \quad t=0, \pm 1, \pm 2, \ldots$

In the equation: $D_{t}$ : demand of customer at t period;

$\mu$ : nonnegative constant;

$\rho$ : relevant coefficient between demands of end customers between two adjacent periods, $|\rho|<1$ is the condition for stable demands

$\varepsilon_{t}$ : change deviation in market demand and $\varepsilon_{t}$ is the random variable to meet mean value is 0 and variance is $\sigma^{2}$ independent identically distributed. Mean value and variance of $D_{t}$ in equation (1).

$$
E\left(D_{t}\right)=\frac{\mu}{1-\rho} \quad \operatorname{Var}\left(D_{t}\right)=\frac{\sigma^{2}}{1-\rho^{2}}(1)
$$

Here we could note that the variable takes different values to represent different demand modes: when $\mu=0$ and $\rho=1$, then the demand is immediate migration procedure; when $\rho=0$, mean value of demand is $\mu$, variance $\sigma^{2}$ independent identically distributed procedure; when $-1<\rho<0$, negatively correlated demands in adjacent two periods, the procedure shows oscillatory behavior; when $0<\rho<1$, positively correlated demands in adjacent two periods, the procedure shows fluctuation trend; when $|\rho| \rightarrow 1$, the demand procedure shows unstable status.

\section{Bullwhip Effect in multi-stage supply chain based on AR(1) demand}

In the last section, we have mainly conducted research on easy two-stage supply chain which is composed of one retailer and one manufacturer. In this section, we would like to expand to the next step to enlarge the level number of the supply chain to 3 levels even level $\mathrm{k}$. Then calculates size of Bullwhip Effect.

When the demand information of the end user is the random procedure based on AR(1), order number $q_{t}^{(1)}$ sent by the first node enterprise to second node enterprise upstream obeys ARMA $(1, \mathrm{P})$ random procedure, that is

$$
q_{t}^{(1)}=\mu+\rho q_{t-1}^{(1)}+\left(1+\frac{L_{1}}{P}\right) \varepsilon_{t}^{(1)}-\frac{L_{1}}{P} \varepsilon_{t-P}
$$

In which superscript(1) means the first node enterprise on the supply chain, similarly (2)means the second node enterprise on the supply chain and so forth. $L_{1}$ is the lead time of first node enterprise on the supply chain. 
To simplify the formula, $\quad\left\{\begin{aligned} \varepsilon_{t}^{(1)}= & \left(1+\frac{L_{1}}{P}\right) \varepsilon_{t}^{(1)} \\ \theta^{(1)} & =\frac{L_{1}}{L_{1}+P}\end{aligned}\right.$

Therefore (2)is simplified as $q_{t}^{(1)}=\mu+\rho q_{t-1}^{(1)}+\varepsilon_{t}^{(1)}-\frac{L_{1}}{L_{1}+P}\left(1+\frac{L_{1}}{P}\right) \varepsilon_{t-P}$

Due to (3) includes the hidden conditions

$\varepsilon_{t-P}^{(1)}=\left(1+\frac{L_{1}}{P}\right) \varepsilon_{t-P}^{(1)}$

Taking (5)into the formula above

$$
\begin{aligned}
& q_{t}^{(1)}=\mu+\rho q_{t-1}^{(1)}+\varepsilon_{t}^{(1)}-\frac{L_{1}}{L_{1}+P} \varepsilon_{t-P}^{(1)}{ }^{\prime} \\
& =\mu+\rho q_{t-1}^{(1)}+\varepsilon_{t}^{(1)}-\theta^{(1)} \varepsilon_{t-P}^{(1)}{ }^{\prime}
\end{aligned}
$$

According to the assumption, the second node enterprise on the supply chain adopts SMA in prediction of demand, then the demand prediction of the second node enterprise on t period is:

$\hat{D}_{t}^{(2)}=\frac{\sum_{i=0}^{P-1} q_{t-i}^{(1)}}{P}$

At the same time the second node enterprise adopts order point system to make order to the third node enterprise, the order amount $q_{t}^{(2)}$ is:

$q_{t}^{(2)}=L_{2}\left(\hat{D}_{t}^{(2)}-\hat{D}_{t-1}^{(2)}\right)+q_{t}^{(1)}$

$L_{2}\left(\frac{\sum_{i=0}^{P-1} q_{t-i}^{(1)}}{P}-\frac{\sum_{i=0}^{P-1} q_{t-1-i}^{(1)}}{P}\right)+q_{t}^{(1)}$

$=L_{2}\left(\frac{q_{t}^{(1)}-q_{t-P}^{(1)}}{P}\right)+q_{t}^{(1)}$

$=\left(1+\frac{L_{2}}{P}\right) q_{t}^{(1)}-\frac{L_{2}}{P} q_{t-P}^{(1)}$

\section{Summary}

The thesis conducts quantitative analysis on Bullwhip Effect mainly in mathematical modeling method, adopting SMA technology to predict market demand, then analyze expansion of Bullwhip Effect by levels, meanwhile adopt predicted ratio of demand variance and real demand variance to measure size of Bullwhip Effect. Adopting auto regression model AR(1) to conduct modeling, mainly involving in easy two-stage supply chain and more complex multi-stage supply chain and obtaining final result of Bullwhip Effect, and conducting analysis on influences of respective relevant factors on Bullwhip Effect and obtaining the conclusion as follows:

Conducting analysis and summary on mechanism of production of Bullwhip Effect including processing of demand signal, delay in delivery time, price fluctuation, ordering in batch, ration and shortage game, network structure of supply chain, environmental variation as well as minimum packing factor and so on, at the same time conducting analysis on hams of Bullwhip Effect. 
For easy two-stage supply chain, during the procedure of prediction of demand, when $L>\sqrt{\frac{P^{2}(1-\rho)^{2}}{P-P \rho^{2}-2 \rho+2 \rho^{P+1}}}$, Bullwhip Effect would occur, meanwhile the larger $L$ is, the larger the value of $\mathrm{A}$ is, which indicates that the more the periods of prediction, the more obvious the Bullwhip Effect is; when $0<L \leq \sqrt{\frac{P^{2}(1-\rho)^{2}}{P-P \rho^{2}-2 \rho+2 \rho^{P+1}}}$, no Bullwhip Effect occurred; particularly, $\rho=0$, Bullwhip Effect is relevant to the ratio of $\frac{L^{2}}{P}$, and A is monotone increasing with it.

For easy two-stage supply chain, during the information transfer, we could get Bullwhip Effect will increase with the increase of time in advance $\mathrm{L}$; the longer the smooth period $\mathrm{P}$ is, Bullwhip Effect will reduce. When $0<\rho<1$, that is, the larger the correlation coefficient $\rho$ is, the smaller the Bullwhip Effect is; when $\rho=0$, Bullwhip Effect is irrelevant to value of $\rho$, only depending on ratio of $\frac{L}{P}$. When $-1<\rho<0$, if $\mathrm{P}$ is the even number, then the larger the correlation coefficient $\rho$ is, the larger the Bullwhip Effect is, if $\mathrm{P}$ is the odd number, then the larger the correlation coefficient $\rho$ is, the smaller the Bullwhip Effect is.

For easy two-stage supply chain, during the information transfer, we could get the same result as that in the information processing. When the demand information of the end customer is AR(1)time series, the retailer adopts SMA prediction method and order point inventory strategy and the information between the manufacturer and the retailer cannot be shared, then demand prediction of the manufacturer is one ARMA ( $1, \mathrm{P})$ random procedure.

For multi-stage supply chain, enterprise node on each stage conforms to $\operatorname{ARMA}(1,1)$ random procedure in order, at the same time we could get expression of the Bullwhip Effect in three-stage supply chain which could be used for digital analysis in the future.

This thesis has put forward some weakening measures aimed at reasons of Bullwhip Effect including strengthening information sharing(EC system, EDI system as well as direct information exchange with consumers through the Internet), adjusting structure of supply chain, preventing shortage game(reducing order batches, shortening time in advance, changing discount method, changing stock allocation mechanism as well as keeping stable price), strengthening inventory control and so on.

\section{References}

[1] Sterman J D. Modeling managerial behavior: misperceptions of feedback in a dynamic decision making experiment. ManagementScience, 1989, 35(3):321-339.

[2] Leeh, Padmanbhan V, Whang S. The bullwhip effect in supply chains. SloanManagementRev, 1997, 38(1):93-102.

[3] Chen F, Drezner Z, Ryan J K, et al. Quantifying the bullwhip effect in a simple supply chain: The impact of forecasting, lead times, and information.Management Science, 2000, 46(3):436-443.

[4] Dejonckheere J, Disney S M, Lambrecht M R, et al. Transfer function analysis of forecasting inducedbullwhip in supply chain. International Journal of Production Economics, 2002, 78(2):133-144.

[5] Marko Jakšič, Borut Rusjan. The effect of replenishment policies on the bullwhip effect: A transfer function approach. European Journal of Operational Research, 2008.02, 184(3): 946-961 
[6] Truong Ton Hien Duc, Huynh Trung Luong, Yeong-Dae Kim. Effect of the third-party warehouse on bullwhip effect and inventory cost in supply chains. International Journal of Production Economics, 2010.04, 124(2):395-407

[7] M.H. Fazel Zarandi, M. Pourakbar, I.B. Turksen. A Fuzzy agent-based model for reduction of bullwhip effect in supply chain systems. Expert Systems with Applications, 2008.04, 34(3):1680-1691 